Review

\title{
Prognostic value of abnormally expressed IncRNAs in ovarian carcinoma: a systematic review and meta-analysis
}

\author{
Ping Luo ${ }^{1}$, Xue-Fang Liư ${ }^{1}$, Ying-Chao Wang ${ }^{1}$, Nan-Di Li ${ }^{1}$, Shen-Jun Liao ${ }^{1}$, Ming-Xia \\ $\mathbf{Y u}^{1}{ }^{1}$, Chun-Zi Liang ${ }^{1}$ and Jian-Cheng Tu ${ }^{1}$ \\ ${ }^{1}$ Department of Clinical Laboratory Medicine \& Center for Gene Diagnosis, Zhongnan Hospital of Wuhan University, Wuhan, \\ China
}

Correspondence to: Jian-Cheng Tu, email: jianchengtu@whu.edu.cn

Keywords: long noncoding RNAs, ovarian cancer, overall survival, prognosis, meta-analysis

Received: November 15, $2016 \quad$ Accepted: January 11,2017

Published: January 19, 2017

\section{ABSTRACT}

Ovarian cancer $(O C)$ is the most deadly gynecological cancer and it is urgently needed to find a new marker for the progress of OC. Many long noncoding RNAs (IncRNAs) have been reported to be aberrantly expressed in ovarian carcinoma, and may serve as prognostic markers. Therefore, we conducted this meta-analysis to gain a better understanding of the prognostic value of IncRNAs in patients with varian carcinoma. We systematically searched PubMed, EMBASE, and Web of Science. A total of 13 eligible studies, including 10 on clinicopathological features, 13 on prognosis were identified. Pooled hazard ratios (HRs) or odds ratios (OR) and $95 \%$ confidence intervals (95\% CIs) were calculated using random- or fixed-effects models. Our results revealed that the increased expressions of 8 IncRNAs were associated with poor prognosis and the decreased expressions of 5 IncRNAs were related to poor prognosis in ovarian carcinoma. High HOTAIR expression was associated with shorter overall survival in ovarian cancer (pooled HR: 2.05, 95\% CI: $1.51-2.77, P<0.001$ ). In conclusion, our meta-analysis suggested that LncRNAs could function as potential prognostic markers for ovarian cancer patients and high expression HOTAIR was associated with shorter overall survival in ovarian cancer.

\section{INTRODUCTION}

Ovarian cancer (OC) is the most deadly gynecological cancer and caused about 140,000 women's death each year [1]. Over the past decade, the improvement of survival rates in ovarian cancer was relatively limited. The 5-year survival rate for patients diagnosed and treated at early stages (I and II) can be over $90 \%$, whereas, most ovarian cancer patients are diagnosed with advanced disease (stages III and IV) and the 5-year survival is less than $30 \%$ [2]. In OC research, several prognostic biomarkers, including mRNAs, such as HuR [3], Notch3 [4] and microRNAs (miRs), such as miR30d [5], miR-200 [6], MiR-9 and miR-223 [7] have been explored. Long non-coding RNAs (lncRNAs) have also been extensively studied because of their significant role in diagnosis, prognosis and treatment.

Long non-coding RNAs (lncRNAs) are a kind of molecules longer than 200bp that can't translate into proteins [8]. It is reported that IncRNAs is involved in various cell biological processes, such as cell proliferation, differentiation, apoptosis, and cell cycle progression [9]. More importantly, emerging evidences have revealed that IncRNAs played critical roles in tumorigenesis [10]. For example, IncRNA-ATB, a lncRNA activated by TGF- $\beta$, is significantly up-regulated in hepatocellular carcinoma and related to poor prognosis [11]. The abnormally expressed Urothelial carcinoma-associated 1 (UCA1) in HCC is correlated with TNM stage, metastasis, survival, and AFP level [12]. Highly up regulated in liver cancer (HULC) is up-regulated in gastric cancer and associated with lymph node metastasis and distant metastasis [13]. Recent studies have shown that lncRNAs also played significant roles in OC [14-16], these findings support that lncRNAs can be developed as diagnostic or prognostic biomarkers in patients with OC.

However, owing to the limitations in sample size and research programs, single study may be inaccurate and insufficient. Thus, studies should be analyzed systematically to uncover the potential clinical values of 
Table 1: Summary of the comparison for the $p$ values of the association between IncRNAs and clinicopathological features

\begin{tabular}{|l|l|l|l|l|l|l|l|l|l|l|}
\hline $\begin{array}{l}\text { Author, year of } \\
\text { publication }\end{array}$ & IncRNAs & $\begin{array}{l}\text { Total } \\
\text { number }\end{array}$ & age & $\begin{array}{l}\text { FIGO } \\
\text { stage }\end{array}$ & LM & $\begin{array}{l}\text { Histological } \\
\text { grade }\end{array}$ & $\begin{array}{l}\text { Residual } \\
\text { tumor } \\
\text { diameter }\end{array}$ & CA125 & Ascites & Expression \\
\hline Qiu [17] 2015 & HOTAIR & 68 & 0.318 & 0.006 & - & 0.011 & 0.604 & 0.465 & 0.618 & Up-regulation \\
\hline Qiu [18] 2014 & HOTAIR & 64 & 0.442 & $<0.001$ & $<0.001$ & 0.001 & 0.157 & 0.209 & 0.784 & Up-regulation \\
\hline Huang [19] 2016 & CCAT2 & 109 & 0.702 & 0.002 & - & 0.006 & - & - & - & Up-regulation \\
\hline Chen [20] 2016 & NEAT1 & 149 & 0.464 & 0.004 & - & 0.009 & - & - & - & Up-regulation \\
\hline Zhang [15] 2016 & UCA1 & 117 & 0.702 & 0.025 & 0.016 & & - & - & - & Up-regulation \\
\hline Yang [21] 2015 & ANRIL & 68 & 0.318 & 0.006 & 0.001 & 0.042 & 0.12 & 0.808 & 0.134 & Up-regulation \\
\hline Fu [23] 2016 & ASAP1-IT1 & 165 & 0.19 & - & - & 0.55 & - & - & - & down-regulation \\
\hline Fu [23] 2016 & FAM215A & 165 & 0.028 & - & - & 0.004 & - & - & - & down-regulation \\
\hline Fu [23] 2016 & LINC00472 & 165 & 0.65 & - & - & 0.004 & - & - & - & down-regulation \\
\hline Qiu [22] 2014 & TC0101441 & 64 & 0.442 & $<0.001$ & - & $<0.001$ & - & - & 0.59 & Up-regulation \\
\hline Teschendorf [24] 2015a & HOTAIR & 134 & 0.166 & 0.733 & - & 0.182 & 0.308 & - & - & Up-regulation \\
\hline Teschendorf [24] 2015b & HOTAIR & 175 & 0.262 & 0.665 & - & 0.483 & 0.161 & - & - & Up-regulation \\
\hline
\end{tabular}

Abbreviations: HOTAIR: HOX transcript antisense RNA; CCAT2: colon cancer associated transcript 2; NEAT1: nuclear paraspeckle assembly transcript 1; UCA1: urothelial carcinoma associated 1; ANRIL: antisense non-coding RNA in the INK4 locus

Table 2: Comparison of the result between Fixed-effects model and Random-effects model

\begin{tabular}{|l|c|c|c|c|}
\hline \multirow{2}{*}{ Clinical features } & \multicolumn{2}{c|}{ Pooled OR (95\% CI) } & \multicolumn{2}{c|}{ Heterogeneity } \\
\cline { 2 - 5 } & Random & Fixed & P (\%) & P-value \\
\hline Age & $0.86(0.53,1.41)$ & $0.88(0.60,1.29)$ & 34 & 0.21 \\
\hline FIGO stage & $3.1(0.98,10.37)$ & $2.35(1.49,3.73)$ & 81 & 0.001 \\
\hline Histological grade & $1.67(0.59,4.74)$ & $1.22(0.83,1.79)$ & 84 & 0.0004 \\
\hline Residual tumor diameter & $1.25(0.84,1.88)$ & $1.26(0.84,1.88)$ & 0 & 0.74 \\
\hline
\end{tabular}

lncRNAs in OC. Until now, only reviews were conducted regarding the evaluation of the clinical values of different lncRNAs in OC, meta-analysis has yet to be performed. Therefore, with the aim to gain a better understanding of the prognostic value of lncRNAs in patients with OC, we carried out a systematic review followed by a metaanalysis of the published articles to explore the prognostic value of lncRNAs in OC.

\section{RESULTS}

\section{Selection process of included studies}

As shown in the flow diagram (Figure 1), 189 articles were retrieved from PubMed, EMBASE, and Web of Science, and 85 duplicated articles were removed, then only 103 articles were left. After we screened the titles and abstracts, 83 irrelevant articles were excluded. Subsequently, the 20 remaining full-text articles were assessed and 8 studies, including 4 review or metaanalysis, 1 with less than 60 sample numbers, 3 with insufficient data were further excluded on the basis of the exclusion criteria. Then 1 articles was identified through reviewing the references. Finally, a total of 13 articles were included in the current meta-analysis.

\section{Correlation of IncRNAs with clinicopathological characteristics of $\mathrm{OC}$}

As shown in Table 1, 9 lncRNAs were involved in the studies described clinicopathological features. HOX transcript antisense RNA (HOTAIR) [17, 18], colon cancer associated transcript 2 (CCAT2) [19], nuclear paraspeckle assembly transcript 1(NEAT1) [20], urothelial carcinoma associated 1(UCA1) [15], antisense non-coding RNA in the INK4 locus (ANRIL) [21] and TC0101441 [22] were up-regulated, whereas ASAP1-IT1, FAM215 and LINC00472 [23] were downregulated. There was no studies reported that lncRNAs were significantly associated with the age, CA125 level and ascites of patients. 3 studies $[15,18,21]$ claimed that up-regulated lncRNAs were significantly related to lymph node metastasis. 6 studies showed that up-regulated lncRNAs were related to Histological grade. All studies except Teschendorf's [24]study demonstrated that lncRNAs were significantly correlated with FIGO stage. 
Table 3: Summary of IncRNAs used as prognostic biomarkers of ovarian cancer

\begin{tabular}{|c|c|c|c|c|c|c|c|c|c|}
\hline $\begin{array}{lll}\begin{array}{l}\text { Author, year } \\
\text { publication }\end{array} & \text { of } \\
\end{array}$ & Country & IncRNAs & \begin{tabular}{|l|}
$\begin{array}{l}\text { Total number } \\
\text { (High/low) }\end{array}$ \\
\end{tabular} & Cutoff & Method & $\begin{array}{l}\text { Internal } \\
\text { reference }\end{array}$ & Outcome & \begin{tabular}{|l|}
$\begin{array}{l}\text { Follow-up } \\
\text { (month) }\end{array}$ \\
\end{tabular} & Quality score \\
\hline Qiu [17] 2015 & China & HOTAIR & $34 / 34$ & Median & qRT-PCR & GAPDH & OS & 100 & 8 \\
\hline Qiu [18] 2014 & China & HOTAIR & $32 / 32$ & Median & qRT-PCR & GAPDH & OS & 80 & 8 \\
\hline Huang [19] 2016 & China & CCAT2 & $55 / 54$ & Median & qRT-PCR & GAPDH & OS & 60 & 7 \\
\hline Li [25] 2016 & China & C17orf91 & $-/-$ & - & qRT-PCR & GAPDH & OS/PFS & 80 & 7 \\
\hline Chen [20] 2016 & China & NEAT1 & $74 / 75$ & Median & qRT-PCR & GAPDH & OS & 70 & 8 \\
\hline Zhang [15] 2016 & China & UCA1 & $59 / 58$ & Median & qRT-PCR & RUN6 & OS & 80 & 8 \\
\hline Yang [21] 2015 & China & ANRIL & $34 / 34$ & Median & qRT-PCR & GAPDH & OS & 100 & 8 \\
\hline Qiu [16] 2015 & China & AB073614 & $38 / 37$ & - & qRT-PCR & GAPDH & OS & 60 & 7 \\
\hline Fu [23] 2016 & Italy & ASAP1-IT1 & $81 / 84$ & Median & qRT-PCR & GAPDH & OS/PFS & 144 & 8 \\
\hline Fu [23] 2016 & Italy & FAM215A & $84 / 77$ & Median & qRT-PCR & GAPDH & OS/PFS & 144 & 8 \\
\hline Fu [23] 2016 & Italy & LINC00472 & $82 / 84$ & Median & qRT-PCR & GAPDH & OS/PFS & 144 & 8 \\
\hline Qiu [22] 2014 & China & TC0101441 & $32 / 32$ & Median & qRT-PCR & GAPDH & OS & 80 & 8 \\
\hline Teschendorf [24]2015a & Austria & HOTAIR & $72 / 62$ & - & qRT-PCR & TBP & OS & 60 & 7 \\
\hline Teschendorf [24] 2015b & Holland & HOTAIR & $117 / 58$ & - & qRT-PCR & TBP & OS & 60 & 7 \\
\hline Guo [26] 2015 & China & RP11-284N8.3.1 & $199 / 200$ & - & DEGseq & - & OS/PFS & 160 & 7 \\
\hline Guo [26] 2015 & China & AC104699.1.1 & $199 / 200$ & - & DEGseq & - & OS/PFS & 160 & 8 \\
\hline
\end{tabular}

Abbreviations: OC: ovarian cancer; qRT-PCR: quantities reverse transcription polymerase chain reaction; GAPDH: glyceraldehyde 3-phosphate dehydrogenase; TBP: TATA-box bingding protein; OS: overall survival; PFS: prognostic free survival

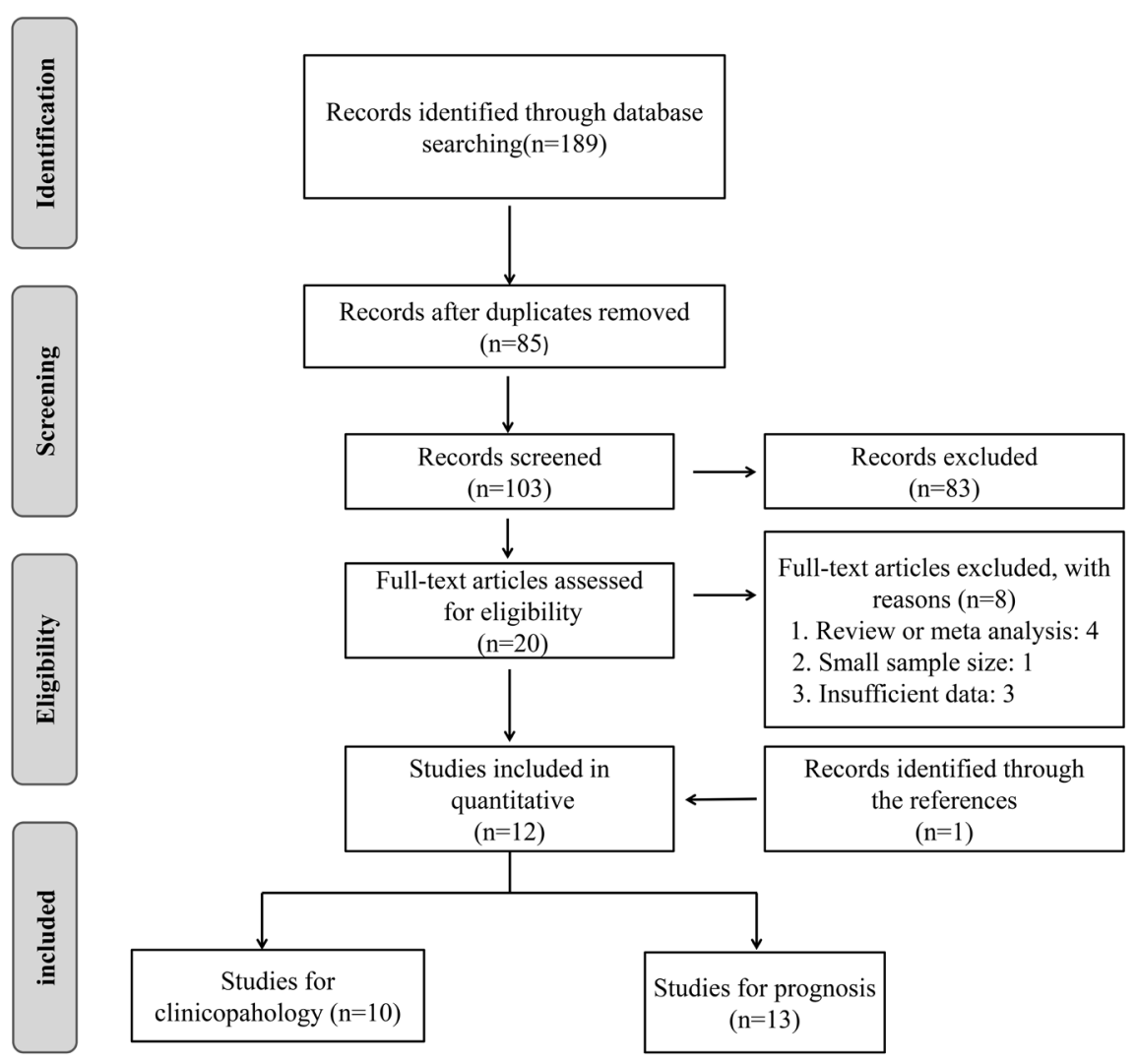

Figure 1: Flow diagram of study selection process. 
There were four studies on HOTAIR, we then explored the relation of HOTAIR and clinicopathological features of OC patients (Figure 2).Significant heterogeneity was observed in FIGO stage $\left(I^{2}=81.0 \%\right)$ and Histological grade $\left.I^{2}=84.0 \%\right)$; however the heterogeneity of age $\left(I^{2}=\right.$ $34.0 \%)$ and residual tumor diameter $\left(I^{2}=0 \%\right)$ were not significant. Therefore, in this part, we compared the result between Fixed-effects model and Random-effects model (Table 2). No significant correlation between up-regulated HOTAIR and clinicopathological features in the Randomeffects model was found although the $P$ value of FIGO stage was 0.05 and a significant association between the expression of HOTAIR and FIGO stage was revealed in Fixed-effects model.

\section{Analysis between IncRNAs expression level and OC survival}

There were 13 studies explored the relationship between lncRNAs and OS of ovarian cancer patients.
Among them, 10 were from China, 1 from Italy, 1 from Austria and 1 from Holland. The included studies were all retrospective and published over the recent three years. 13 different lncRNAs were associated with the prognosis of patients with OC. The characteristics of these 13 eligible studies are presented in Table 3 . The increased expressions of HOTAIR [17, 18], CCAT2 [19], NEAT1 [20], C17orf91 [25], UCA1 [15], ANRIL [21], AB073614 [16] and TC0101441 [22] were associated with poor prognosis; similarly, the decreased expressions of ASAP1IT1, FAM215, LINC00472 [23] and RP11-284N8.3.1 AC104699.1.1 [26] were related to poor prognosis (Figure $3)$. With all the lncRNAs, HOTAIR generated the highest hazard ratio (HR) of 3.64 [24]; by contrast, AC104699.1.1 [26] exhibited the lowest HR of 0.50 .

Four studies investigated the association between the expression of HOTAIR and OS in a total number of 441 patients, we then conducted a meta-analysis on the relationship of HOTAIR expression and the overall survival (OS) of patients with ovarian cancer; As the heterogeneity was not significant $\left(I^{2}=18.0 \%, P=0.30\right)$, a

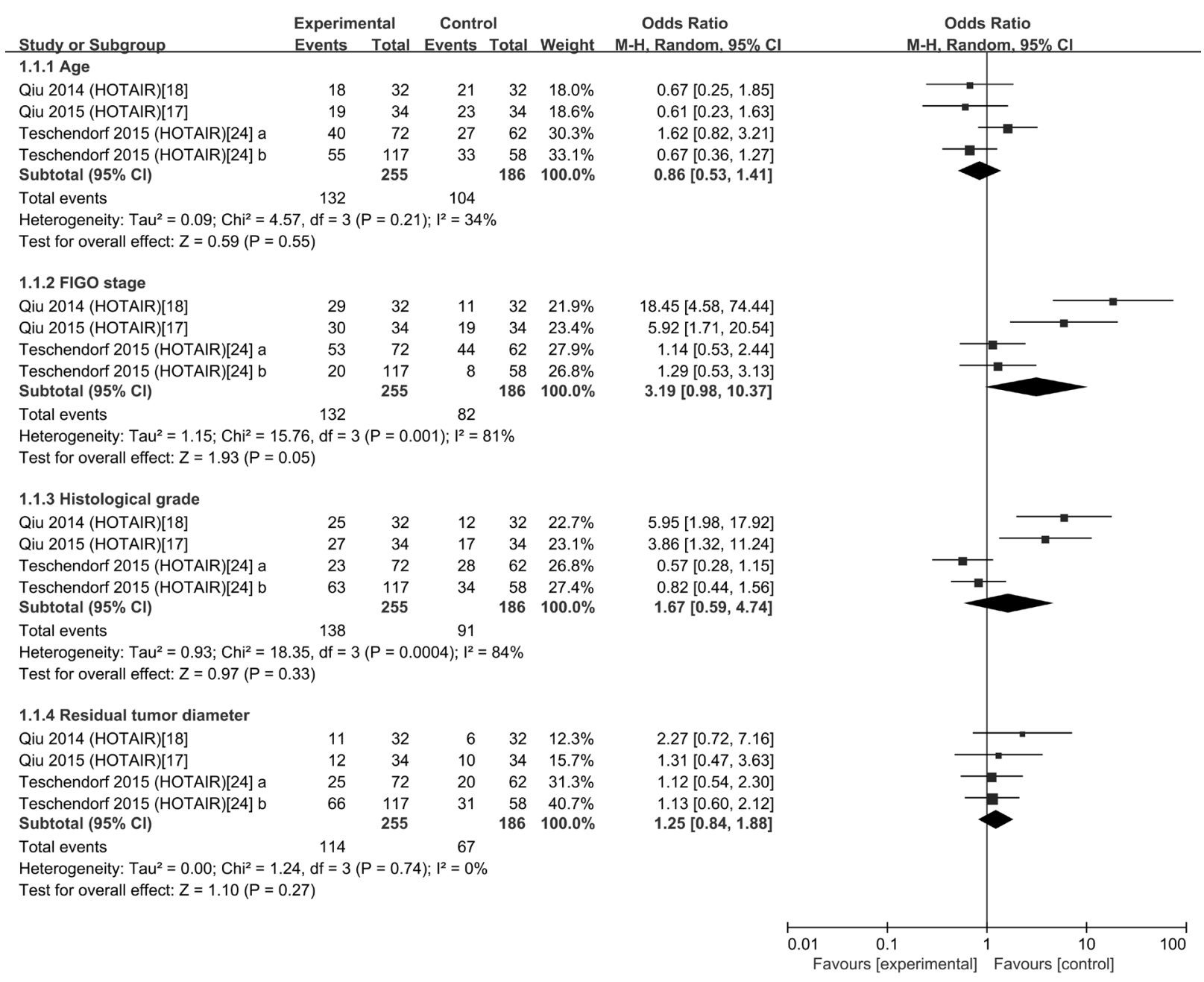

Figure 2: Forest plots of studies evaluating odds ratios (ORs) of HOTAIR expression and the clinicopathology of OC patients. 
fixed effects model was applied. The model revealed that high HOTAIR expression was associated with shorter OS in ovarian cancer (pooled HR: 2.05, 95\% CI: 1.51-2.77, $P$ $<0.001$ ) (Figure 4).

\section{Sensitivity analysis and publication bias}

Stata11.0 software was used to perform sensitivity analysis to assess whether the individual studies affected the overall results. The results revealed that individual study had little influence on our final results (Figure 5) and validated the reliability of our results. Egger's test was used to evaluate the publication bias. The $P$ value of the Egger's test was 0.015, which was $>0.01$ but $<0.05$, it indicated that there was publication bias existed in this meta-analysis.

\section{DISCUSSION}

With the development of technology, increasing evidence demonstrated that aberrant expression of
lncRNAs were associated with clinical outcomes for cancer patients. Multiple studies have revealed that lncRNAs were involved in the onset and progression of cancer including apoptosis, metastasis, migration, and other clinical outcome [27]. LncRNAs may exert their roles through the following ways: (1) interfering in the expression of the adjacent encoding protein gen [28]; (2) binding with functional protein [29]; (3) acting as the precursors of miRNAs and affecting on target genes of miRNA [30]; (4) regulating signaling pathway through combing with chromosome [31].

Recently, more and more studies found that aberrant expression of multiple lncRNAs were involved in the tumorigenesis and may have prognostic value for OC [32]. Gao et al. [33] demonstrated that HOST2 was overexpressed in ovarian cancer and the tumorigenic effects of HOST2 were dependent on its ability to act as a molecular sponge for let-7b. Zou et al. [34] found that MALAT1 was up-regulated in ovarian cancer tissue and promoted SK-OV-3 cell proliferation and invasion. In order to have a better understanding between lncRNAs and $\mathrm{OC}$, further to identify a prognostic marker for $\mathrm{OC}$,

\begin{tabular}{l} 
Study or Subgroup \\
\hline Chen 2016(NEAT1)[20] \\
Fu 2016 (ASAP1-IT1)[23] \\
Fu 2016 (FAM215A)[23] \\
Fu 2016 (LINC00472)[23] \\
Guo 2015 (AC104699.1.1)[26] \\
Guo 2015 (RP11-284N8.3.1)[26] \\
Huang 2016(CCAT2)[19] \\
Li 2016 (C17orf91)[25] \\
Qiu 2014 (HOTAIR)[18] \\
Qiu 2014 (TC0101441)[22] \\
Qiu 2015 (AB073614)[16] \\
Qiu 2015 (HOTAIR)[17] \\
Teschendorf 2015 (HOTAIR)[24] a \\
Teschendorf 2015 (HOTAIR)[24] b \\
Yang 2015 (ANRIL)[21] \\
Zhang 2016 (UCA1)[15]
\end{tabular}

$\begin{array}{rr}\text { log[Hazard Ratio] } & \text { SE } \\ 1.1115 & 0.417 \\ -0.5798 & 0.2398 \\ -0.3011 & 0.2538 \\ -0.1278 & 0.2398 \\ -0.6992 & 0.3735 \\ -0.4186 & 0.1871 \\ 1.0777 & 0.3342 \\ 0.5596 & 0.3011 \\ 0.8525 & 0.4164 \\ 0.8167 & 0.4021 \\ 0.6471 & 0.3302 \\ 0.6397 & 0.3208 \\ 1.292 & 0.365 \\ 0.4886 & 0.2293 \\ 0.6392 & 0.317 \\ 0.5235 & 0.2646\end{array}$

Hazard Ratio Hazard Ratio

IV. Fixed, $95 \% \mathrm{Cl} \quad$ IV. Fixed, $95 \% \mathrm{Cl}$

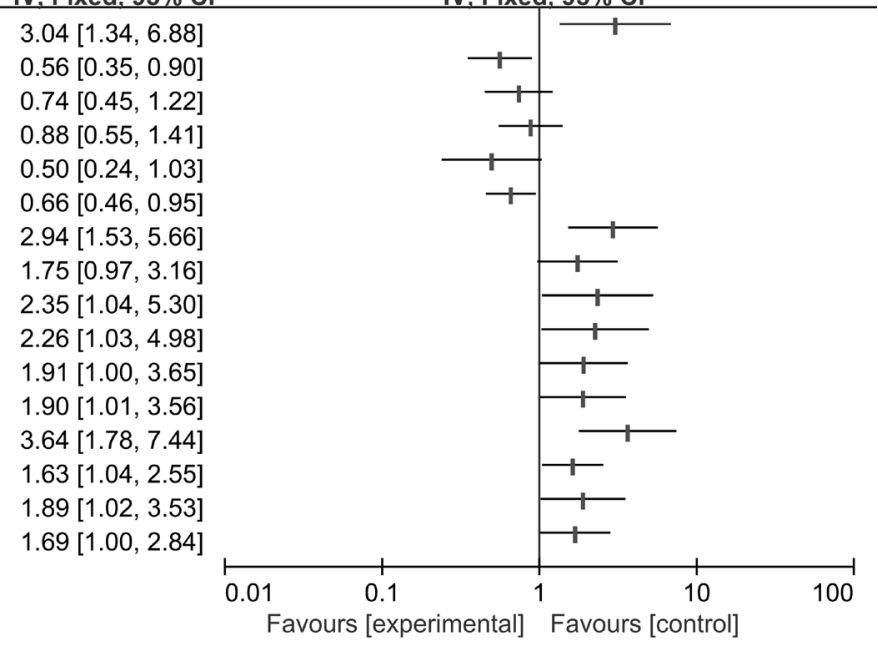

Figure 3: A display of Hazard ratios (HRs) of IncRNAs in OC patients. The point estimate is bounded by a $95 \%$ confidence interval, and the perpendicular line represents no increased risk for the outcome. OC: ovarian cancer.

\begin{tabular}{|c|c|c|c|c|c|c|c|c|c|}
\hline Study or Subgroup & log[Hazard Ratio] & SE & Weight & $\begin{array}{l}\text { Hazard Ratio } \\
\text { IV. Fixed. } 95 \% \mathrm{Cl}\end{array}$ & & $\begin{array}{r}\text { Hazard } \\
\text { IV. Fixed }\end{array}$ & $\begin{array}{l}\text { d Ratio } \\
\text { d. } 95 \% \mathrm{Cl}\end{array}$ & & \\
\hline Qiu 2014 (HOTAIR)[18] & 0.8525 & 0.4164 & $13.7 \%$ & $2.35[1.04,5.30]$ & & & & & \\
\hline Qiu 2015 (HOTAIR)[17] & 0.6397 & 0.3208 & $23.1 \%$ & $1.90[1.01,3.56]$ & & & & & \\
\hline Teschendorf 2015 (HOTAIR)[24] a & 1.292 & 0.365 & $17.9 \%$ & $3.64[1.78,7.44]$ & & & & & \\
\hline Teschendorf 2015 (HOTAIR)[24] b & 0.4886 & 0.2293 & $45.3 \%$ & $1.63[1.04,2.55]$ & & & & & \\
\hline Total $(95 \% \mathrm{Cl})$ & & & $100.0 \%$ & $2.05[1.51,2.77]$ & & & & & \\
\hline $\begin{array}{l}\text { Heterogeneity: } \mathrm{Chi}^{2}=3.64, \mathrm{df}=3( \\
\text { Test for overall effect: } Z=4.65(P<\end{array}$ & $\begin{array}{l}=0.30) ;\left.\right|^{2}=18 \% \\
.00001)\end{array}$ & & & & 0.01 & $\begin{array}{c}0.1 \\
\text { Low expression }\end{array}$ & 1 & $\begin{array}{l}10 \\
\text { ression }\end{array}$ & 100 \\
\hline
\end{tabular}

Figure 4: Forest plots for the association between HOTAIR expression and OS of OC patients. The point estimate is bounded by a $95 \%$ confidence interval, and the perpendicular line represents no increased risk for the outcome. OS: overall survival; OC: ovarian cancer. 
we carried out this comprehensive systematic review and meta-analysis of the current literature.

Up to now, two meta-analyses $[35,36]$ evaluated the association between lncRNAs and cancer survival involved $\mathrm{OC}$ as one of the cancer sites. Both of these two studies focused on exploring association between lncRNA UCA1 or MALAT-1 and OS in all human cancers, ovarian cancer is just one of them. Our article, on the other hand, with quite different goal, was mainly focused on all lncRNAs that related to OC. Therefore the present meta-analysis is the first to explore the association between lncRNAs expression and clinical features of OC comprehensively.

In the present meta-analysis, we found that the increased expressions of 8 lncRNAs were associated with poor prognosis; similarly, the decreased expressions of 5 lncRNAs were related to poor prognosis in OC. Summary of Hazard ratios (HRs) of lncRNAs in OC patients showed that HOTAIR generated the highest hazard ratio (HR) of 3.64 [24]; by contrast, AC104699.1.1 [26] exhibited the lowest HR of 0.50 . HOTAIR was the most investigated lncRNA and reported by four studies, the pooled HR showed that high HOTAIR expression was significantly associated with shorter OS in ovarian cancer. We then explored the relation between HOTAIR expression and clinicopathological characteristics. Because of the different $I^{2}$ value among the subgroup, Fixed-effects model and Random-effects model were both used. We found that high HOTAIR expression was discovered to be associated with high FIGO stage in Fixed-effects model, in the Random-effects model, although the result was not significant, the $P$ value was 0.05 , which is almost smaller than 0.05 , representing a high likelihood of a repeatable difference.

Our meta-analysis demonstrated that HOTAIR was correlated with OC prognosis but not Histological grade. Qiu et al. [17, 18] reported that high HOTAIR expression was associated with high histological grade (G3). However, Teschendorf et al. [24] did not find any association between increased HOTAIR expression and grade, the first two studies [17, 18] included ovarian carcinoma patients with serous or epithelial subtype, whereas the third study [24] included all subtypes (serous, mucinous, endometrioid, clear cell) as well as fallopian tube and non-classifiable tumors, which may explain this discrepancy. HOTAIR is an IncRNA expressed from the HOXC locus on chromosome 12 [37]. Studies reported that HOTAIR acted as a scaffold lncRNA binding to both

Meta-analysis fixed-effects estimates (exponential form) Study ommited

Chen 2016(NEAT1)[20]
Fu 2016 (ASAP1-IT1)[23]
Fu 2016 (FAM215A)[23]

Fu 2016 (LINC00472)[23]

Guo 2015 (AC104699.1.1)[26]

Guo 2015 (RP11-284N8.3.1)[26]

Huang 2016(CCAT2)[19]

Li 2016 (C17orf91)[25]

Qiu 2014 (HOTAIR)[18]

Qiu 2014 (TC0101441)[22]

Qiu 2015 (AB073614)[16]

Qiu 2015 (HOTAIR)[17]

Teschendorf 2015 (HOTAIR)[24] a

Teschendorf 2015 (HOTAIR)[24] b

Yang 2015 (ANRIL)[21]

Zhang 2016 (UCA1)[15]

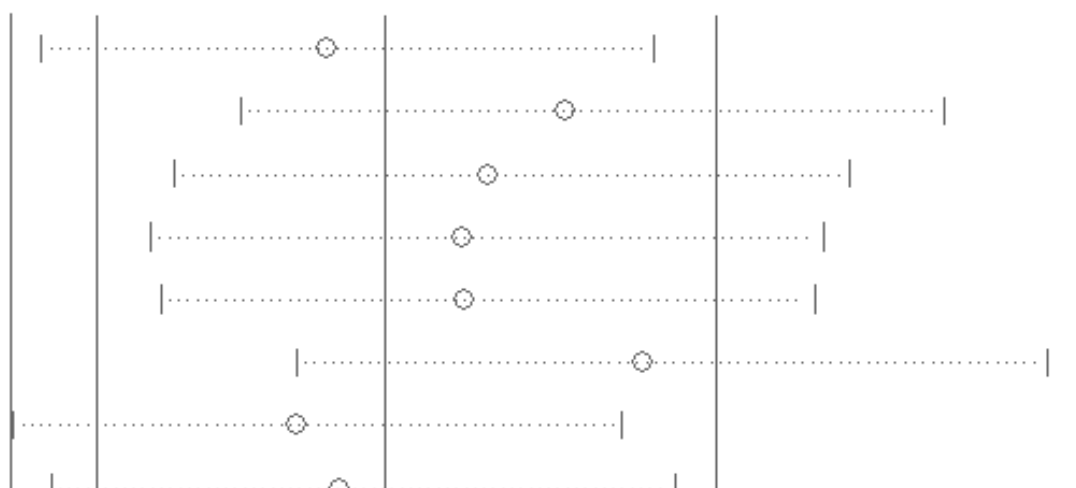

(1)

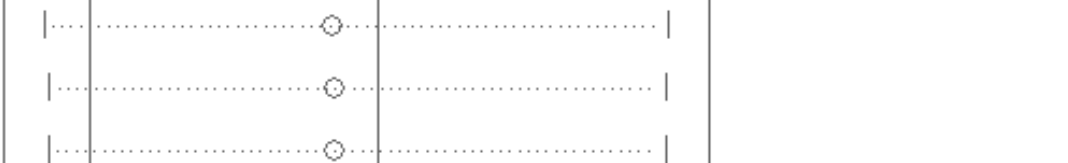

(1)

]

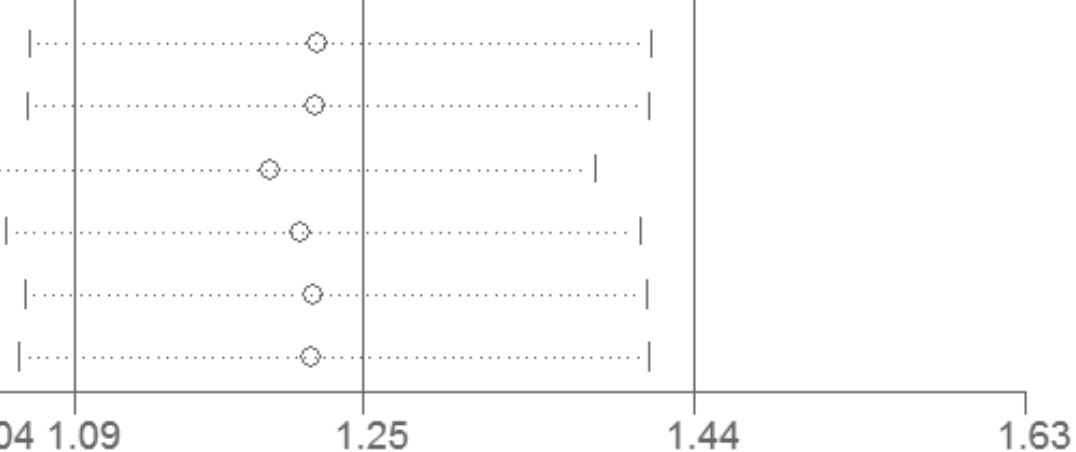

Figure 5: Sensitivity analysis of the influence of each individual study on the pooled HRs by omitting individual studies. 
PRC2 and LSD1 histone modification complexes through its 5' and 3' domains respectively [38].

HOTAIR is aberrantly expressed in a variety of human cancers, such as breast cancer [39], colorectal cancer [40], laryngeal squamous cell carcinoma [41], and liver cancer [42]. The up-regulation of the HOTAIR expression was related to poor prognostic outcome of different cancers, those findings in consist with our results. HOTAIR was the most investigated IncRNA in OC, therefore, articles explored HOTAIR in OC is possibly the most promising.

It should be stressed that there were limitations in our analysis. Firstly, the cutoff value and method for low or high levels of lncRNA varied in different studies, which may cause the heterogeneity of results; secondly, different lncRNAs were used to assess the prognosis of $\mathrm{OC}$, leading to lack of specific OC-related lncRNA for clinical evaluation; thirdly, since in most cases there was only one study for each lncRNA, we may overestimated the prognostic value of each lncRNA; fourthly, publication bias is a concern, language restriction of our analysis to published studies written in English may result in publication bias, furthermore, the fact that negative results are more difficult to be published maybe also contributed to the publication bias.

In conclusion, our study for the first time evaluated the correlation between lncRNAs and clinical characteristics of patients with OC. Despite the existence of limitations, the present study revealed that lncRNAs could be considered as biomarkers for FIGO stage and Histological grade. We also found that lncRNAs could be used as potential prognostic markers for OC and high HOTAIR expression could predict poor survival among patients with OC. However, in view of the limitation of individual studies about lncRNAs, in future, further comprehensive, large-scale, and good quality studies should be conducted to confirm our findings and thus promote the clinical utility of lncRNAs in evaluating ovarian patients' prognosis

\section{MATERIALS AND METHODS}

\section{Search strategy}

We searched the databases PubMed, EMBASE, and Web of Science for studies that relevant about the prognostic value of IncRNA in OC. The search ended in November 2016. The search terms used were:("Long noncoding RNA", "IncRNA", "LincRNA", "Long ncRNA", "Long intergenic non-coding RNA") AND ("ovarain cancer", "ovarain tumor", "ovarain carcinoma", "ovarain neoplasm"). Additionally, we screened the references of retrieved relevant articles to identify potentially eligible literatures.

\section{Inclusion and exclusion criteria}

The inclusion criteria were as follows: (1) studies investigated the expression of IncRNAs in OC, (2) studies described the relationship between IncRNA expression and overall survival (OS) and sufficient data to estimate hazard ratios (HRs) for survival rates and their $95 \%$ confidence interval , (3) studies published in English. Exclusion criteria were as follows: (1) studies without usable data, (2) duplicate publications, (3) sample cases fewer than 60, (4) reviews, letters, single case reports, (5) animal studies, (6) HRs calculated on the basis of multiple lncRNAs.

\section{Data extraction and quality assessment}

Two investigators (Ping Luo and Xue-Fang Liu) retrieved the data independently and the following information was extracted: (1) publication information: first author, year of publication; (2) patients' characteristic information: study population, sample size, and followup duration; (3) lncRNA information: detection methods, cut-off definition, and relationship between lncRNAs and survival outcome or clinicopathological features; (4) HRs, $95 \%$ CI for survival analysis. Studies explored the expression level of lncRNAs in different data set were considered to be different studies. The quality assessment of non-randomized studies is an important component of a thorough meta-analysis of non-randomized studies, so Newcastle-Ottawa Scale (NOS) criteria was used to assess the quality of the included studies [43]. Ping Luo and Xue-Fang Liu independently assessed the Quality of the included studies. Any disagreements were resolved through discussing with Ying-Chao Wang.

\section{Statistical analysis}

All analyses were performed using the STATA software version 11.0 (Stata Corporation, College Station, Texas, USA) or Review Manager version 5.3. HR and 95\% CIs were used to assess the association between IncRNAs and $\mathrm{OS}$ in OC, as to the relation between lncRNAs and clinical features, ORs and 95\% CIs were used. We got HRs with their $95 \%$ CIs directly from data in articles or from Kaplan-Meier survival curves using Engauge Digitizer version 4.1 [44]. Fixed-effects model was used when there was no significant heterogeneity $\left(\mathrm{I}^{2} \leq 50 \%\right.$ or $P \geq 0.05$ ) between studies, otherwise, the random-effects model was used [45]. An observed HR $>1$ implied a worse survival for the group with elevated lncRNA expression and an observed HR $<1$ implied a better survival for the group with increased lncRNA expression. Sensitivity analysis was conducted by omitting the study sequentially. Publication bias was evaluated using the funnel plot with Egger's test, $P<0.05$ was considered statistically significant. 


\section{CONFLICTS OF INTEREST}

The authors declare no conflict of interest.

\section{GRANT SUPPORT}

This study was supported by the National Basic Research Program of China (973 Program) (2012CB720605) and the development of Homer ELISA kit for breast cancer detection (201260523173-2).

\section{Author contributions}

Ping Luo, Xue-Fang Liu and Ying-Chao Wang contributed for study search, quality check, data extraction, and drafting. Nan-Di Li and Shen-Jun Liao carried out the statistical analysis. Ming-Xia Yu, Chun-Zi Liang and Jian-Cheng Tu critically revised the manuscript. All authors reviewed and finally approved the manuscript.

\section{REFERENCES}

1. Meryet-Figuiere M, Lambert B, Gauduchon P, Vigneron N, Brotin E, Poulain L, Denoyelle C. An overview of long non-coding RNAs in ovarian cancers. Oncotarget. 2016; 7: 44719-44734. doi: 10.18632/oncotarget.8089.

2. Shapira I, Oswald M, Lovecchio J, Khalili H, Menzin A, Whyte J, Dos Santos L, Liang S, Bhuiya T, Keogh M, Mason C, Sultan K, Budman D, et al. Circulating biomarkers for detection of ovarian cancer and predicting cancer outcomes. Br J Cancer. 2014; 110: 976-83. doi: 10.1038/bjc. 2013.795

3. Davidson B, Holth A, Hellesylt E, Hadar R, Katz B, Trope CG, Reich R. HUR mRNA expression in ovarian highgrade serous carcinoma effusions is associated with poor survival. Hum Pathol. 2016; 48: 95-101. doi: 10.1016/j. humpath.2015.09.027.

4. Zhou X, Teng L, Wang M. Distinct prognostic values of four-Notch-receptor mRNA expression in ovarian cancer. Tumour Biol. 2016; 37: 6979-85. doi: 10.1007/s13277-0154594-5.

5. Lee H, Park CS, Deftereos G, Morihara J, Stern JE, Hawes SE, Swisher E, Kiviat NB, Feng Q. MicroRNA expression in ovarian carcinoma and its correlation with clinicopathological features. World J Surg Oncol. 2012; 10: 174. doi: 10.1186/1477-7819-10-174.

6. Hu X, Macdonald DM, Huettner PC, Feng Z, El Naqa IM, Schwarz JK, Mutch DG, Grigsby PW, Powell SN, Wang X. A miR-200 microRNA cluster as prognostic marker in advanced ovarian cancer. Gynecol Oncol. 2009; 114: 45764. doi: 10.1016/j.ygyno.2009.05.022.

7. Laios A, O'Toole S, Flavin R, Martin C, Kelly L, Ring M, Finn SP, Barrett C, Loda M, Gleeson N, D’Arcy T,
McGuinness E, Sheils O, et al. Potential role of miR-9 and miR-223 in recurrent ovarian cancer. Mol Cancer. 2008; 7: 35. doi: 10.1186/1476-4598-7-35.

8. Shi H, Cao N, Pu Y, Xie L, Zheng L, Yu C. Long noncoding RNA expression profile in minor salivary gland of primary Sjogren's syndrome. Arthritis Res Ther. 2016; 18: 109. doi: 10.1186/s13075-016-1005-2.

9. Venkatraman A, He XC, Thorvaldsen JL, Sugimura R, Perry JM, Tao F, Zhao M, Christenson MK, Sanchez R, Yu JY, Peng L, Haug JS, Paulson A, et al. Maternal imprinting at the H19-Igf2 locus maintains adult haematopoietic stem cell quiescence. Nature. 2013; 500: 345-9. doi: 10.1038/ nature 12303

10. Tsai MC, Spitale RC, Chang HY. Long intergenic noncoding RNAs: new links in cancer progression. Cancer Res. 2011; 71: 3-7. doi: 10.1158/0008-5472.can-10-2483.

11. Yuan JH, Yang F, Wang F, Ma JZ, Guo YJ, Tao QF, Liu F, Pan W, Wang TT, Zhou CC, Wang SB, Wang YZ, Yang $\mathrm{Y}$, et al. A long noncoding RNA activated by TGF-beta promotes the invasion-metastasis cascade in hepatocellular carcinoma. Cancer Cell. 2014; 25: 666-81. doi: 10.1016/j. ccr.2014.03.010.

12. Wang F, Ying HQ, He BS, Pan YQ, Deng QW, Sun HL, Chen J, Liu X, Wang SK. Upregulated IncRNA-UCA1 contributes to progression of hepatocellular carcinoma through inhibition of miR-216b and activation of FGFR1/ ERK signaling pathway. Oncotarget. 2015; 6: 7899-917. doi: 10.18632/oncotarget.3219.

13. Jin C, Shi W, Wang F, Shen X, Qi J, Cong H, Yuan J, Shi L, Zhu B, Luo X, Zhang Y, Ju S. Long non-coding RNA HULC as a novel serum biomarker for diagnosis and prognosis prediction of gastric cancer. Oncotarget. 2016; 7: 51763-51772. doi: 10.18632/oncotarget.10107.

14. Zhou M, Sun Y, Sun Y, Xu W, Zhang Z, Zhao H, Zhong $Z$, Sun J. Comprehensive analysis of lncRNA expression profiles reveals a novel lncRNA signature to discriminate nonequivalent outcomes in patients with ovarian cancer. Oncotarget. 2016; 7: 32433-48. doi: 10.18632/ oncotarget.8653.

15. Zhang L, Cao X, Zhang L, Zhang X, Sheng H, Tao K. UCA1 overexpression predicts clinical outcome of patients with ovarian cancer receiving adjuvant chemotherapy. Cancer Chemother Pharmacol. 2016; 77: 629-34. doi: 10.1007/s00280-016-2963-4.

16. Cheng Z, Guo J, Chen L, Luo N, Yang W, Qu X. A long noncoding RNA AB073614 promotes tumorigenesis and predicts poor prognosis in ovarian cancer. Oncotarget. 2015; 6: 25381-9. doi: 10.18632/oncotarget.4541.

17. Qiu JJ, Wang Y, Ding JX, Jin HY, Yang G, Hua KQ. The long non-coding RNA HOTAIR promotes the proliferation of serous ovarian cancer cells through the regulation of cell cycle arrest and apoptosis. Exp Cell Res. 2015; 333: 23848. doi: 10.1016/j.yexcr.2015.03.005.

18. Qiu JJ, Lin YY, Ye LC, Ding JX, Feng WW, Jin HY, Zhang 
Y, Li Q, Hua KQ. Overexpression of long non-coding RNA HOTAIR predicts poor patient prognosis and promotes tumor metastasis in epithelial ovarian cancer. Gynecol Oncol. 2014; 134: 121-8. doi: 10.1016/j.ygyno.2014.03.556.

19. Huang S, Qing C, Huang Z, Zhu Y. The long non-coding RNA CCAT2 is up-regulated in ovarian cancer and associated with poor prognosis. 2016; 11: 49. doi: 10.1186/ s13000-016-0499-x.

20. Chen ZJ, Zhang Z, Xie BB, Zhang HY. Clinical significance of up-regulated lncRNA NEAT1 in prognosis of ovarian cancer. Eur Rev Med Pharmacol Sci. 2016; 20: 3373-7.

21. Qiu JJ, Lin YY, Ding JX, Feng WW, Jin HY, Hua KQ. Long non-coding RNA ANRIL predicts poor prognosis and promotes invasion/metastasis in serous ovarian cancer. Int J Oncol. 2015; 46: 2497-505. doi: 10.3892/ijo.2015.2943.

22. Qiu JJ, Ye LC, Ding JX, Feng WW, Jin HY, Zhang Y, Li Q, Hua KQ. Expression and clinical significance of estrogenregulated long non-coding RNAs in estrogen receptor alpha-positive ovarian cancer progression. Oncol Rep. 2014; 31: 1613-22. doi: 10.3892/or.2014.3000.

23. Fu Y, Biglia N, Wang Z, Shen Y, Risch HA, Lu L, Canuto EM, Jia W, Katsaros D, Yu H. Long non-coding RNAs, ASAP1-IT1, FAM215A, and LINC00472, in epithelial ovarian cancer. Gynecol Oncol. 2016. doi: 10.1016/j. ygyno.2016.09.021.

24. Teschendorff AE, Lee SH, Jones A, Fiegl H, Kalwa M, Wagner W, Chindera K, Evans I, Dubeau L, Orjalo A, Horlings HM, Niederreiter L, Kaser A, et al. HOTAIR and its surrogate DNA methylation signature indicate carboplatin resistance in ovarian cancer. Genome Med. 2015; 7: 108. doi: 10.1186/s13073-015-0233-4.

25. Li J, Yu H, Xi M, Lu X. Long noncoding RNA C17orf91 is a potential prognostic marker and functions as an oncogene in ovarian cancer. J Ovarian Res. 2016; 9: 49. doi: 10.1186/ s13048-016-0258-3.

26. Guo Q, Cheng Y, Liang T, He Y, Ren C, Sun L, Zhang G. Comprehensive analysis of lncRNA-mRNA co-expression patterns identifies immune-associated lncRNA biomarkers in ovarian cancer malignant progression. Sci Rep. 2015; 5: 17683. doi: 10.1038/srep17683.

27. Wang TH, Lin YS, Chen Y, Yeh CT, Huang YL, Hsieh TH, Shieh TM, Hsueh C, Chen TC. Long non-coding RNA AOC4P suppresses hepatocellular carcinoma metastasis by enhancing vimentin degradation and inhibiting epithelialmesenchymal transition. Oncotarget. 2015; 6: 23342-57. doi: 10.18632/oncotarget.4344.

28. Khalil AM, Rinn JL. RNA-protein interactions in human health and disease. Semin Cell Dev Biol. 2011; 22: 359-65. doi: 10.1016/j.semcdb.2011.02.016.

29. Huarte M, Guttman M, Feldser D, Garber M, Koziol MJ, Kenzelmann-Broz D, Khalil AM, Zuk O, Amit I, Rabani M, Attardi LD, Regev A, Lander ES, et al. A large intergenic noncoding RNA induced by p53 mediates global gene repression in the p53 response. Cell. 2010; 142: 409-19. doi: 10.1016/j.cell.2010.06.040.

30. Cesana M, Cacchiarelli D, Legnini I, Santini T, Sthandier O, Chinappi M, Tramontano A, Bozzoni I. A long noncoding RNA controls muscle differentiation by functioning as a competing endogenous RNA. Cell. 2011; 147: 358-69. doi: 10.1016/j.cell.2011.09.028.

31. Nagano $T$, Fraser P. No-nonsense functions for long noncoding RNAs. Cell. 2011; 145: 178-81. doi: 10.1016/j. cell.2011.03.014.

32. Meryet-Figuiere M, Lambert B, Gauduchon P, Vigneron N, Brotin E, Poulain L, Denoyelle C. An overview of long non-coding RNAs in ovarian cancers. Oncotarget. 2016; 7: 44719-34. doi: 10.18632/oncotarget.8089.

33. Gao Y, Meng H, Liu S, Hu J, Zhang Y, Jiao T, Liu Y, Ou J, Wang D, Yao L, Liu S, Hui N. LncRNA-HOST2 regulates cell biological behaviors in epithelial ovarian cancer through a mechanism involving microRNA let-7b. Hum Mol Genet. 2015; 24: 841-52. doi: 10.1093/hmg/ddu502.

34. Zou A, Liu R, Wu X. Long non-coding RNA MALAT1 is up-regulated in ovarian cancer tissue and promotes SKOV-3 cell proliferation and invasion. Neoplasma. 2016. doi: 10.4149/neo_2016_605.

35. Hong HH, Hou LK, Pan X, Wu CY, Huang H, Li B, Nie W. Long non-coding RNA UCA1 is a predictive biomarker of cancer. Oncotarget. 2016; 7: 44442-7. doi: 10.18632/ oncotarget.10142.

36. Wang Y, Xue D, Li Y, Pan X, Zhang X, Kuang B, Zhou M, Li X, Xiong W, Li G, Zeng Z, Yang T. The Long Noncoding RNA MALAT-1 is A Novel Biomarker in Various Cancers: A Meta-analysis Based on the GEO Database and Literature. J Cancer. 2016; 7: 991-1001. doi: 10.7150/jca.14663.

37. Rinn JL, Kertesz M, Wang JK, Squazzo SL, Xu X, Brugmann SA, Goodnough LH, Helms JA, Farnham PJ, Segal E, Chang HY. Functional demarcation of active and silent chromatin domains in human HOX loci by noncoding RNAs. Cell. 2007; 129: 1311-23. doi: 10.1016/j. cell.2007.05.022.

38. Tsai MC, Manor O, Wan Y, Mosammaparast N, Wang JK, Lan F, Shi Y, Segal E, Chang HY. Long noncoding RNA as modular scaffold of histone modification complexes. Science. 2010; 329: 689-93. doi: 10.1126/science.1192002.

39. Gupta RA, Shah N, Wang KC, Kim J, Horlings HM, Wong DJ, Tsai MC, Hung T, Argani P, Rinn JL, Wang Y, Brzoska P, Kong B, et al. Long non-coding RNA HOTAIR reprograms chromatin state to promote cancer metastasis. Nature. 2010; 464: 1071-6. doi: 10.1038/nature08975.

40. Kogo R, Shimamura T, Mimori K, Kawahara K, Imoto S, Sudo T, Tanaka F, Shibata K, Suzuki A, Komune S, Miyano S, Mori M. Long noncoding RNA HOTAIR regulates polycomb-dependent chromatin modification and is associated with poor prognosis in colorectal cancers. Cancer Res. 2011; 71: 6320-6. doi: 10.1158/0008-5472. can-11-1021. 
41. Li D, Feng J, Wu T, Wang Y, Sun Y, Ren J, Liu M. Long intergenic noncoding RNA HOTAIR is overexpressed and regulates PTEN methylation in laryngeal squamous cell carcinoma. Am J Pathol. 2013; 182: 64-70. doi: 10.1016/j. ajpath.2012.08.042.

42. Yang Z, Zhou L, Wu LM, Lai MC, Xie HY, Zhang F, Zheng SS. Overexpression of long non-coding RNA HOTAIR predicts tumor recurrence in hepatocellular carcinoma patients following liver transplantation. Ann Surg Oncol. 2011; 18: 1243-50. doi: 10.1245/s10434-011-1581-y.
43. Stang A. Critical evaluation of the Newcastle-Ottawa scale for the assessment of the quality of nonrandomized studies in meta-analyses. Eur J Epidemiol. 2010; 25: 603-5. doi: 10.1007/s10654-010-9491-z.

44. Tierney JF, Stewart LA, Ghersi D, Burdett S, Sydes MR. Practical methods for incorporating summary time-toevent data into meta-analysis. Trials. 2007; 8: 16. doi: 10.1186/1745-6215-8-16.

45. DerSimonian R, Laird N. Meta-analysis in clinical trials. Control Clin Trials. 1986; 7: 177-88. 